\title{
The accuracy of interpreting key psychiatric terms by ad hoc interpreters at a South African psychiatric hospital
}

\author{
S Hagan', L Swartz', S Kilian', B Chiliza², P Bisogno', J Joska ${ }^{3}$ \\ ${ }^{1}$ Centre for Public Mental Health, Department of Psychology, Stellenbosch University, South Africa \\ 2Department of Psychiatry, Stellenbosch University, South Africa \\ ${ }^{3}$ Department of Psychiatry and Mental Health, University of Cape Town, Cape Town, South Africa
}

\begin{abstract}
Objective: This study examined the competence and accuracy of ad hoc interpreters in interpreting key psychiatric terms at a South African psychiatric hospital. Method: Nine individuals were asked to translate key psychiatric terms from English to Xhosa. These translations were then back-translated by independent translators, who do not have knowledge of psychiatric terminology. These back-translations were then compared with the original English. Results: It was clear that not all the participants were fully competent in English. None had formal training in interpreting or psychiatric terminology. Not all of the participants were familiar with the psychiatric concepts that clinicians use and they often made mistakes while interpreting. Conclusion: The competency levels of interpreters are unsatisfactory to ensure the optimal delivery of mental health care. It is clear that there is a need for trained interpreters in South Africa, as the continuous use of untrained interpreters compromises the effectiveness of mental health care and could lead to adverse health outcomes.
\end{abstract}

Keywords: Translation; Cultural Diversity; South Africa; Health Care Quality; Access and Evaluation

Received: 30-07-2012

Accepted: 14-01-2013

doi: http://dx.doi.org/10.4314/ajpsy.v16i6.54

\section{Introduction}

Communication lies at the heart of psychiatric treatment language has been described as the "raw material" of psychiatry and mental health practitioners as the instrument through which this raw material is converted into meaningful psychiatric data. ${ }^{1}$ The effectiveness of psychiatric care depends largely on whether clinicians and patients understand each other. Without effective communication, a language and cultural barrier may exist between clinician and patient. This is a major challenge standing in the way of the optimal delivery of health care. ${ }^{2}$ The effectiveness of health care, i.e. the understanding of psychiatric diagnoses, signs and symptoms depends largely on the understanding of key psychiatric concepts. ${ }^{3}$ Psychopathological symptoms are often not directly observable on interview; clinicians thus need a good and thorough history of their patient and the disorder. Bolton ${ }^{4}$ suggests that there are three tasks that a clinician is expected to do. The first of these is to establish rapport and trustworthiness. ${ }^{4}$ Secondly it is important that the clinician understands the patient's problems. ${ }^{4}$ The third and final task of a clinician is to attempt to help a patient with their problems. ${ }^{4}$ Without a common language these three tasks are very difficult. Bolton" suggests that "unfamiliar words are the most salient instances of cultural distance between doctor and patient" (p. 103). Words may differ in terms of denotation and connotation. Concepts like depression and psychosis may have a clear denotative meaning, but there may be considerable differences in the connotative meaning of these words for clinician and patient. Language barriers are not uncommon in a country like South Africa, which has 11 official languages, yet many clinicians can only speak one or two of these languages. ${ }^{5}$

Language barriers in psychiatry are of concern in many countries. The USA and the UK, for example, have a growing number of migrant populations with limited English proficiency (LEP). A lack of proficiency in the dominant languages spoken in the host country brings with it a number of barriers and 
complications to mental health care. Some consequences of limited proficiency in dominant languages include poor access to medical care, excess hospitalisations, lower-quality care, medical errors and poor satisfaction with care. ${ }^{6.7}$ There is evidence that suggests that individuals with LEP in the USA were less likely to receive mental health services than those with English proficiency. ${ }^{8}$ In addition to a language barrier, there also may be cultural barriers. According to Kim et al ${ }^{8}$, cultural differences include differences in willingness to report psychological problems and expressing them publicly. Cultural diversity plays an important role in South Africa's mental health services. Not only do clinicians and patients speak different languages, but they bring with them unique cultural backgrounds. White, monolingual clinicians often have to work with patients that are from a different language group and that have different cultural beliefs and traditions, which is a daunting task. ${ }^{9}$

Where language barriers exist, interpreters are sometimes used. The term "interpreter" usually refers to a person who transfers the denotative as well as connotative meaning of a word or words in a spoken situation (as opposed to the term "translator" which refers to a person who translates written texts). ${ }^{10}$ Interpreters can have a significant impact on the success of mental health services and must manage the dynamics of the clinician-patient interaction. ${ }^{10}$ Interpreters must not only be fluent in both languages used; they commonly must also mediate cultural differences between clinician and patient. ${ }^{11}$ The 'third presence' of interpreters solves the immediate problem of the language barrier, but it creates other difficulties for the patient and clinician. ${ }^{4}$

The use of professional interpreters has been associated with some benefits, which include the fact that they have been trained, are thought to be more accurate, ensure confidentiality and have knowledge of medical terms and the medical system..$^{12}$ In resource-limited settings (RLS), clinicians may access interpreters from various professional groups in an ad hoc way. Although there are several difficulties associated with the use of ad hoc interpreters, the provision of adequate interpreter services imposes an extra financial burden. ${ }^{13}$ Clinicians often have to rely on the services of ad hoc interpreters in the absence of being multilingual themselves or having access to a professional interpreter. ${ }^{2}$ Ad hoc interpreters may have inadequate language proficiency and may lack psychiatric knowledge, which can result in errors in interpreting. They may not have the dual fluency needed. It is also likely that they do not have the necessary technical vocabulary. Problems with interpretation may arise as a result of these challenges. Difficulties in interpretation include the omission of information, bad paraphrasing, lack of translatable words or concepts, inaccurate translation of words or concepts, distortion of meaning, exaggeration, lack of familiarity with professional terminology, inability to interpret the cultural meaning of the symptoms and behaviour and the inability to detect paralinguistic or nonverbal behaviour. ${ }^{14-16}$ The most fundamental difficulty is whether the interpreter can speak both languages and whether he/she can translate terms accurately. With the use of informal or ad hoc interpreters there are also a number of ethical issues that need to be addressed. These include respect for patient autonomy, informed consent, patient confidentiality and patient privacy. ${ }^{15,17}$ Although there are many drawbacks to using ad hoc interpreters, clinicians in RLS are often pressed to use any available person with bilingual ability. ${ }^{15}$ Although there are certain issues with regards to working with ad hoc interpreters, MacFarlane et al. ${ }^{15}$ note that a greater number of people have a preference for working with ad hoc interpreters in comparison to professional interpreters, citing accessibility as the primary reason. Patients felt that the presence of an interpreter was beneficial, in the sense that they had a better understanding. ${ }^{6}$ Nurses are increasingly called upon to act as interpreters. ${ }^{18,19}$ During interpretation, it is important for the clinicians to articulate on points that the interpreter might be unsure, "proceeding slowly and systematically with their queries, reflecting information back to the interpreter for back-translation and patient verification" ( $\mathrm{p}$. 1356). ${ }^{19}$ Ad hoc interpreters should also be encouraged to translate the full cultural idioms that organise patient's symptoms, instead of heavily edited versions. ${ }^{19}$

Although there are eleven languages that enjoy official status in South Africa, this country's political history has marginalised the indigenous African languages and there is a largely monolingual, English-centred approach to health care. ${ }^{5}$ According to Schlemmer and Mash², most health care workers can only speak one or two of South Africa's official languages - generally, English and/or Afrikaans, despite the fact that in the Western Cape for example Xhosa is also an official language..$^{20}$

Patients are expected to communicate in English, as it is often viewed as a lingua franca and is seen as bridging the communication gap between different language groups. ${ }^{21}$ Nurses are often the only health care professionals that can speak any of the indigenous languages., $5,22,23$

As has already been mentioned, psychiatrists need to understand their patients and the patients need to understand them. However it is important to note that this must go far beyond mere conversational competence, as mental health workers need to "make a complex range of contextualised inferences based on the content of what is said and on how it is said" (p. 1853). ${ }^{1}$

In South Africa, health workers other than nurses are often used as ad hoc interpreters ${ }^{1.19 .2}$, but other personnel, who are not trained in health care, are also used. These include cleaners and security guards. ${ }^{20}$ As Kilian et al ${ }^{20}$ have shown, we know very little about the use of security guards and cleaners as ad hoc interpreters. Kilian et $\mathrm{al}^{20}$ have done a study in one South African hospital in which security guards were used as ad hoc interpreters. These authors found considerable challenges to accurate interpreting in this group, not least of which was the fact that people acting as interpreters were not fluent in English. The question arises as to whether this was an isolated instance at a single institution. This study therefore replicates that of Kilian et $\mathrm{al}^{20}$, in a different hospital setting.

\section{Method}

\section{Research design}

As part of a larger study, a cross-sectional qualitative interview design was used to assess the accuracy and language proficiency of ad hoc interpreters. Furthermore, participants took part in a written competency test, in which they were asked to translate commonly-used diagnostic terms. Interviews were audio-taped.

\section{Participants}

The sample comprised nine ward security officers at a major South African mental hospital. All nine participants were male and Xhosa speaking. All participants were employees of a private security firm working at a major psychiatric hospital in Cape Town. Participants were chosen on the basis that they acted as interpreters in exceptional circumstances at the institution. They were however not employed specifically as interpreters and did interpreting as the exception rather than the rule. The participants were chosen on the basis of convenience. 


\section{Procedure}

SH and PB interviewed the participants by way of a semistructured framework. Participants were interviewed in a relaxed and informal manner, in order for them to feel that they could express their opinions freely. (The content of the interviews, which covered the participants' views on and experiences of doing informal interpreting will be reported on elsewhere.) Participants were assured that the interview material was for research and not for audit purposes. The interviews took place at the participants' place of employment. In addition to the semistructured interviews, a written competency test was given to each participant. The participants were asked to translate nine diagnostic questions from English into Xhosa and to give backtranslations in English of their own translated items. The aim of the competency test was to gain an indication of whether the participants could give accurate translations. In addition to the competency test, participants were asked to reflect on their multilingual skills and experience of working as an interpreter Participants were asked what languages they spoke and how fluently they perceived themselves speaking each language. The translations were checked by a team of independent backtranslators, using the following method. Each translation was checked by two independent back-translators; no backtranslator was used more than once. Each back-translator was only asked to do one translation, as we did not want them to be influenced by previous translations. The criteria for the backtranslators were that they were first language Xhosa speakers, second language English speakers and not working in the mental health field. They were associated with the African languages department at a South African university.

\section{Analysis}

The audio-taped interviews were transcribed verbatim. Content analysis was used to analyse the transcribed data. Content analysis entails the collecting and analysis of textual data. ${ }^{24}$ The aim of this is to identify certain themes within the multiple words of the text and code in accordingly.

The independent translators' back translations and the participants Xhosa translations and back translations were entered into various tables. We then compared the independent translators' back translations and the participants Xhosa translations and back translations with one another. We then compared the back translations of both the independent translators' and the participants with the original psychiatric phrases.

\section{Ethics}

This study was approved by the Health Research Ethics Committee of Stellenbosch University (Approval number NO9/05/162). All protocols regarding confidentiality, informed consent, and other ethical issues were adhered to.

\section{Results}

Even before the competency test was conducted, it was evident that not all the participants were fully bilingual. One of the participants couldn't do the competency test. Examples from interviews are presented below to illustrate difficulties and problems in the translation of psychiatric terms and general communication (Table I). Some of the participants had difficulty understanding the questions, as illustrated below.
Interviewer (SH): Okay, now how did you, how did you become an unofficial interpreter? Did they ask you one day or did you tell them that you can do the job?

Participant (P5): I want the job if the job is coming

SH: Okay

P5: Because this job is not right sometimes

SH: Which job?

P5: Job of security

SH: Do you prefer the interpreting job?

P5: I want if have a job, but if a... if job of secur... no, eh, interpreting is coming, I take job.

Some of the participants admitted that they were not fluent in English and said that they use the interpreting sessions as a way to learn English. Exchanges with some of the security guards are presented below to illustrate this.

P3:You see, what happens. I can, willing to be an interpreter, if I can be trained, if I can be trained, because I was not trained. I talk English; I was not even much fluent in English, because most of the time I stay with my people, you understand?

P6:Ya, I enjoy it because me also I get eh a lot of things there from that doctor because I like to learn Afrikaans and English, ya.

The majority of the participants stated that it was sometimes difficult to translate the terms that the clinicians used, as there were no direct translated Xhosa words for the terms. Below is an extract from the interview process to illustrate this.

P1: My friends it's okay, at other times you see, okay the doctor calls us to maybe answer a question you see. When you are just putting it Xhosa, in Xhosa, you must try to explain it; you don't have a proper word you see. That's maybe, the doctor is asking you about allergies, you can't just put it straight in Xhosa, we don't have a name to go with allergy. Now you've got to try and explain it to the patient in the right way, you see.

All nine participants stated that they had no training in interpreting or psychiatric terms and most of them had little to no previous experience as an interpreter, as illustrated below.

SH: Ok, and before you worked here did you work in any other job where you had to translate?

P9: No, before I worked here, I come from the, I was work for the tiling...

The participants may have had little experience as interpreters, but all of them were interested in receiving training as interpreters and saw it as an opportunity of getting a better job. Their biggest concern however, was who would pay for the training. Some of the exchanges we had with the participants illustrate this.

P1:Yes, I am interested, but okay, because of funds you see, it's a difficult time. I have an interest in it, because I just enjoy in working in psyche environment, ja.

Some of the participants acknowledged that they sometimes get frustrated, because it was sometimes difficult to understand the 
patients, the patients might not understand the interpreters and they were aware that they themselves make mistakes and leave out material.

P1: At times I can get frustrated, because I try. You give the question to the patient you see, and it's always going in the wrong way. You want to put it in the right way. Ja, and I'm telling you know, you can't continue with that translation.

One of the participants saw the need for professional interpreters, instead of using security guards. Some of the participants also realised the importance of interpreting and they acknowledged that with the help of interpreters, patients could be discharged earlier. One participant did however comment that he did not like it when the clinician asked him questions about the patient. This is illustrated below.

P1: They must appoint people to translate. They mustn't use security as translators.

P9: ... Sometimes I can help to find other translation for me, I can help for the patient to get discharged, you see. Although the doctor don't discharge he can keep him for long time but the doctor sometimes when he has heard enough by the questions for me to answer for me he can tell me the fight of the patient. Oh, this patient is so and so, he can give the patient stuff, sometimes I like to see the patient get discharged after I help him. I, it's not the tablets it may be for that translation.

Four of the nine participants stated that they gave direct, word for word translations, whereas the others thought it more appropriate to rather convey the clinician's words in their own meaning, making it easier for the patients to understand.

P7: No, I just interpret word for word. Yes.

P9: Yes, I sometimes have the doctor asks the question is look like a paragraph, I don't tell, tell, explain all that paragraph, I just finish him what does that whole paragraph is saying, that, that main point of that paragraph, you see. And then I ask it.

The security guards often worked with the patients a lot more than the clinician did, so they could have valuable input on the state of the patients if they receive the proper training. That being said, they did not always want to speak about the patients to the clinician. Exchanges with some of the security guards are presented below to illustrate this.

P7: No, I don't like, because they ask me I must just interpret for the patient, you can't ask me how the patient is look like. Ja, my job is just to interpret and then when I'm finished, I'm out.

Most of the participants gave direct translations for the following diagnostic questions: "Do you hear voices?" "Have you been bewitched?" "Are you afraid that people want to hurt or poison you?" "The majority of the participants did however use different phrases and words in addition to or replacing the original diagnostic questions. In examining the back-translations of the independent translators, we found a lot of discrepancies in the way the participants translated the diagnostic questions. Examples are provided in Table I. Although there was no formal method of assessing the interpreter's competency, it is obvious that many of them had major difficulty in translating some of the diagnostic questions.

\section{Discussion}

The most striking finding with respect to language issues could be seen in the interviews themselves - there was miscommunication between the researcher and at least half of the participants. Even though the questions were put to them in simple English, some participants did not understand all of the questions. Some of the participants admitted to not being fluent in English and said that they used the interpreting sessions to learn English and also to learn more about interpreting. Quite apart from any other skills, any interpreter must understand both languages used.

One of the major difficulties for the interpreters in this study was the terms the doctors use, as there aren't always directly equivalent words in Xhosa, e.g. for the term depression. According to Westermeyer and Janca ${ }^{3}$, understanding psychiatric diagnoses, signs and symptoms relies on the understanding of key psychiatric concepts, which is fundamental to the effectiveness of the delivery of mental health care. None of the participants had the necessary interpreter training or training in psychiatric terminology to act as an interpreter, which is especially demanding in the context of psychiatric care. It seems that clinicians called on security guards to interpret only on the basis that they were Xhosa speaking. That being said, it is important to note that the participants were only used as interpreters in extreme situations.

Furthermore, some of the participants admitted to getting frustrated during interpreting sessions, as there were sometimes misunderstandings between all three parties involved and this could have the result that the patient may lose confidence in the clinician and/or interpreter. This lack of confidence in the clinician and/or interpreter can have the result that it is difficult to establish rapport and trustworthiness, which is one of the most fundamental tasks that a clinician must do. ${ }^{4}$ Some of the participants were also aware that they sometimes made mistakes while interpreting, which also frustrated them. One of the participants expressed the need for the involvement of professional interpreters in the hospital. Karliner et $\mathrm{al}^{25}$ point out that the use of professional interpreters in situations where a language barrier exists has a positive impact on the clinical care of patients. There was a general consensus that the participants realised the important role an interpreter might play in ensuring effective psychiatric treatment and although most of them liked to help out as interpreters and even thought of it as being part of their job, one participant expressed that he sometimes felt resentful about this, because his job was to be a security guard. Two other participants stated that security guards shouldn't be used as interpreters, with one expressing that he would not like to do more interpreting in the future. This raises the issue of 'division of labour', as the security guards are sometimes expected to interpret in addition to their role as a security guard.

Although the majority of participants had very little experience as interpreters, all of them showed an interest in learning more and getting training. The participants cited financial issues as the main obstacle they would face if they would receive training. They had concerns over paying for the training themselves and they had concerns over being away from their work during training, as they were dependent on their salaries.

As there are not always direct translations for some of the 
Table I: Examples of translations and back-translations of diagnostic questions by study participants and two independent translators

Back translation

Back translation

\begin{tabular}{|c|c|c|c|c|}
\hline Question and Participant & Xhosa translation & ${ }^{*}$ By participant & By first translator & By second translator \\
\hline $\begin{array}{l}\text { Do you hear voices? } \\
\text { Participant } 6\end{array}$ & UnezintoOzivayo & You hear voices? & Do you hear things? & Do you hear things? \\
\hline
\end{tabular}

Do you have special powers

or abilities?

Participant 6

Do you have special powers or abilities?

Participant 2

uThixouyathethanawe

God is speaking to you?

Does God speak to you?

Do God speak to you?

\begin{tabular}{l} 
Po \\
\hline Dou feel sad?
\end{tabular}

Do you feel sad
Participant 7

Do you feel depressed?

Participant 5

Do you feel depressed?

Participant 8

Do you feel anxious?
Participant 8

Participant 8

\begin{tabular}{|l} 
\\
\hline Have you felt excessively \\
happy, irritable or energetic? \\
Participant 3 \\
Have you felt excessively \\
happy, irritable or energetic? \\
Participant 6
\end{tabular}

\section{Participant 6}

Have you lost interest in pleasurable activities? Participant 2

Have you lost interest in
pleasurable activities?
Participant 6

Uzivauxnwalekile, uhlelelekile
Ungabaulahlekelwe ngumdlaukwenzeni izintookanyeezemidlalo

Uzivawonwabilek

wayeunamandla

Uzivanjani?

Izntookanyeezemidlalo

Uhlala phi?

Ingabaunoloyikolo

mAtuongakubethayo?
Do you have special powers

Do you have special powers Do you have the power to to help people?

help others or to pray for them?

Do you perhaps have powers to help people or can you pray for them?

Are you afraid?

\begin{tabular}{|l|l|}
\hline You are sad & Are you scared?
\end{tabular}

You are feel distressed?

Do you feel tired?

Do you feel tired?

Do you feel separate, do you sometimes feel you are alone, do you feel all alone all your life?

Uzivaungenamandlaungavuji?

Can you feel you don't have the power, you unhappy you see, you not glad you see?

Are you feel happy or the
energetic?

What do you feel?

Do you feel like you lost interest in playing in any kind of sport or anything to help like just being energetic something like that

Where do you stay?

Do you feel you are afraid for someone can beat you or someone can hurt you, do you feel someone can hate you?
Do you feel worthless and ashamed of yourself?

Do you feel down and out and poor?

Do you feel weak and unhappy?

Do you feel powerless and unhappy?

You feel happy and powerful?

You feel happy or strong?

?

How do you feel?

How are you feeling?

Have you lost interest in

doing things or in sport?

Have you lost interest in

doing things that interest you? power?
Do you feel any fear of a person who might beat/hurt you?

*Note: We reproduce here the translations exactly as produced by the informal interpreters. We have not corrected errors of spelling or usage of Xhosa terms. 
words and terms the clinicians use, additional and substitute words are often necessary and quite useful to ensure that misunderstandings are reduced or even eliminated. That being said, without the necessary training, additional and substitute words can often distort the meaning of a question. For example "Are you scared?" does not convey the same meaning as "Do you feel sad?" Similarly, "Do you feel like you lost interest in playing in any kind of sport or anything to help like just being energetic something like that" or "Have you lost interest in doing things or in sport?" is not an adequate alternative for "Have you lost interest in pleasurable activities?"

\section{Conclusion}

The study was limited in scope. Not all the issues pertaining to interpreting could be addressed, the most important of which concerns the question of the accuracy of interpretation conducted by these informal interpreters. For this we would have had to observe actual interpreted sessions. Despite these limitations, the findings have important implications. The most important finding is that, as in the study by Kilian and her colleagues in another hospital20, people who are called upon to work as informal interpreters in mental health care may not be able to speak the languages of both clinician and client. It is a basic assumption of work on interpretation in health care that interpreters are fluent in both languages, but we found that not all ad hoc interpreters could speak English, which is the language in which clinicians were working.

Even where a person is competent or partially competent in a second language, this does not qualify them to act as an interpreter. It is essential for individuals who act as interpreters to receive the necessary interpreting and psychiatric training to ensure that mental health care provision is effective to all. It is the right of the patient to communicate in their home language, especially where that language is an official language. ${ }^{20} \mathrm{~A}$ pilot project is currently underway which is exploring the use of dedicated interpreters who have received basic training in both psychiatry and interpreting skills.

\section{Acknowledgements}

We are grateful to the board of the hospital concerned for permission to conduct the study and to publish, and to all the participants. We are grateful for the very helpful comments from peer review. Financial support for this study was provided by the South African Medical Research Council. All views in this article are those of the authors alone and not those of any other person or organization.

\section{References}

1. Drennan G, Swartz L. The paradoxical use of interpreting in psychiatry. Social Science \& Medicine 2002; 54:1853-1866.

2. Schlemmer A, Mash B. The effects of a language barrier in a South African district hospital. South African Medical Journal 2006; 96:10841087.

3. Westermeyer J, Janca A. Language, culture and psychopathology: Conceptual and methodological issues. Transcultural Psychiatry 1997; 34:291-311.

4. Bolton J. The third presence: A psychiatrist's experience of working with non-English speaking patients and interpreters. Transcultural Psychiatry 2002; 39:97-114.

5. Deumert A. 'It would be nice if they could give us more language' Serving South Africa's multilingual patient base. Social Science \&
Medicine 2010; 71:53-61.

6. Bauer AM, Alegria MA. Impact of patient language proficiency and interpreter service use on the quality of psychiatric care: A systematic review. Psychiatric Services 2010; 61:765-773.

7. Carrasquillo O, Orav EJ, Brennan TA, Burstin HR. Impact of language barriers on patient satisfaction in an emergency department. Journal of General Internal Medicine 1999; 14:82-87.

8. Kim G, AguadoLoi CX, Chiriboga DA, Jang Y, Parmelee P, Allen RS. Limited English proficiency as a barrier to mental health service use: A study of Latino and Asian immigrants with psychiatric disorders. Journal of Psychiatric Research 201 1; 45:104-1 10.

9. Swartz L, Drennan G. Beyond words: Notes on the 'irrelevance' of language to mental health services in South Africa. Transcultural Psychiatry 2000; 37:185-201.

10. Swartz L. Culture and mental health: A southern African view. Cape Town: Oxford University Press (Chapter 2, pp. 25-51.).

11. Hsieh E. Interpreters as co-diagnosticians: Overlapping roles and services between providers and interpreters. Social Science \& Medicine 2007; 64:924-937.

12. Rosenburg E, Leanza Y, Seller R. Doctor-patient communication in primary care with an interpreter: Physician perceptions of professional and family interpreters. Patient Education and Counseling2007; 67:286292.

13. Jacobs EA, Shepard DS, Suaya JA, Stone E. Overcoming language barriers in health care: Costs and benefits of interpreter services. American Journal of Public Health 2004; 94:866-869.

14. Baker DW, Hayes R, Fortier JP. Interpreter use and satisfaction with interpersonal aspects of care for Spanish-speaking patients.Medical Care 1998; 36:1461-1470.

15. MacFarlane A, Glynn LG, Mosinkie PI, Murphy AW. Response to language barriers in consultations with refugees and asylum seekers: A telephone survey of Irish general practitioners. BMC Family Practice 2008; 9:1-6.

16. Meeuwesen L, Twilt S, ten Thilje JD, Harmsen H. "Ne diyor?" (What does she say?): Informal interpreting in general practice. Patient Education and Counseling2009; 81:198-203.

17. Bezuidenhout $L$, Borry P. Examining the role of informal interpretation in medical interviews. Journal of Medical Ethics 2009; 35:159-162.

18. Bischoff A, Bovier PA, Isah R, Françoise G, Ariel E, Louis L. Language barriers between nurses and asylum seekers: Their impact on symptom reporting and referral. Social Science \& Medicine 2003; 57:503-512.

19. Elderkin-Thompson $V$, Silver RC, Waitzkin H. When nurses double as interpreters: A study of Spanish-speaking patients in a US primary care setting.Social Science \& Medicine 2001; 52:1343-1358.

20. Kilian S, Swartz L, Joska J. Competence of interpreters in a South African psychiatric hospital in translating key psychiatric terms. Psychiatric Services 2010; 61:309-312.

21. Williams $M$, Bekker S. Language policy and speech practice in Cape Town: An exploratory public health sector study. South African Linguistic and Applied Language Studies 2008; 26:171-183.

22. Drennan G. Psychiatry, post-apartheid integration and the neglected role of language in South African institutional contexts. Transcultural Psychiatry 1999; 36:5-22.

23. Levin ME. Language as a barrier to care for Xhosa-speaking patients at a South African paediatric teaching hospital. South African Medical Journal 2006; 96:1076-1079.

24. Hsieh H-F, Shannon SE. Three approaches to qualitative content analysis. Qualitative Health Research 2005; 15: 1277-1288.

25. Karliner LS, Jacobs EA, Chen AH, Mutha S. Do professional interpreters improve clinical care for patients with limited English proficiency? A systematic review of the literature. Health Services Research 2007; 42:727-754. 